in vivo $34: 2269-2276(2020)$

doi:10.21873/invivo.12037

\title{
Reverse Transcriptase Affects Gametogenesis and Preimplantation Development in Mouse
}

\author{
CHRYSOULA KITSOU ${ }^{1 *}$, LEANDROS LAZAROS ${ }^{1,2}$, ALEXANDRA PAPOUDOU-BAI $^{3}$, \\ PRODROMOS SAKALOGLOU $^{1}$, EIRINI MASTORA ${ }^{1}$, THEODOROS LYKOVARDAKIS ${ }^{1}$, \\ KATERINA GIAKA ${ }^{1}$, GEORGIOS VARTHOLOMATOS ${ }^{4}$, IOANNA BOUBA ${ }^{1}$, \\ SOFIA MARKOULA ${ }^{5}$, ANNA BATISTATOU ${ }^{3}$ and IOANNIS GEORGIOU ${ }^{1}$ \\ ${ }^{1}$ Laboratory of Medical Genetics of Human Reproduction, Medical School, Ioannina University, Ioannina, Greece; \\ ${ }^{2}$ Genesis Genoma Lab, Genetic Diagnosis-Clinical Genetics-Research, Athens, Greece; \\ ${ }^{3}$ Department of Pathology, Ioannina University Hospital, Ioannina, Greece; \\ ${ }^{4}$ Laboratory of Hematology, Molecular Biology Unit, Ioannina University Hospital, Ioannina, Greece; \\ ${ }^{5}$ Department of Neurology, Ioannina University Hospital, Ioannina, Greece
}

\begin{abstract}
Background/Aim: The expression of reverse transcriptase $(R T)$ in ovaries, testes, gametes and embryos highlights its critical role in cell growth and differentiation. We sought to investigate the effects of the potent RT inhibitor lamivudine in gametogenesis and mouse embryo preimplantation development. Materials and Methods: Male and female $F V B / N$ mice were treated with the reverse transcriptase inhibitor Lamivudine for seven consecutive weeks. Following treatment, mouse sperm parameters, testicular and ovarian morphology as well as post-IVF embryo development were evaluated. Results: Lamivudine impaired the sperm parameters and the testicular structure in male mice, the number of primordial germ cells and primary oocytes in ovaries of female mice, and the embryos' morphology and development up to the blastocyst stage during in vitro culture. Conclusion: The administration of lamivudine affected the processes of spermatogenesis and oogenesis as well as the in vitro preimplantation development of mouse embryos.
\end{abstract}

This article is freely accessible online.

${ }^{*}$ Present address: Department of Veterinary Medicine, University of Maryland, College Park, MD, U.S.A.

Correspondence to: Ioannis Georgiou, Ph.D., Professor of Medical Genetics and Clinical Embryology, Laboratory of Medical Genetics of Human Reproduction, Medical School, Ioannina University, 45110 Ioannina, Greece. Tel: +30 2651099783, Fax: +30 2651099224,e-mail: igeorgio@uoi.gr

Key Words: Lamivudine, spermatogenesis, oogenesis, embryogenesis, antiretroviral drugs, reverse transcriptase.
The enzyme reverse transcriptase (RT) generates complementary DNA (cDNA) from an RNA template through a process called reverse transcription and has been primarily associated with the retroviral life cycle. In eukaryotic cells, RT activity is essential for the telomerase function and the mobilization of retrotransposable elements. Both telomerase and retrotransposons are highly expressed in transformed and undifferentiated cells, such as cancer and germ cells (1-6).

Telomerase is a ribonucleoprotein complex composed by a catalytic subunit of telomerase reverse transcriptase (TERT), telomerase RNA components (TERC) and binding proteins (7). It is localized at the end of eukaryotic chromosome and synthesizes telomeric repeats by reverse transcription. Telomerase activity has been observed in human fetal, newborn and adult testes and ovaries, but not in mature spermatozoa and oocytes (8). Specifically, high telomerase expression levels have been found in spermatogonia and in primary spermatocytes of adult testes, while decreased expression levels have been detected in secondary spermatocytes; however, no expression has been observed in spermatids and in epididymal or ejaculated spermatozoa (9). Regarding oocytes, telomerase is expressed at the early antral and preovulatory follicles, while it is significantly decreased during ovulation and oocyte maturation $(7,9)$.

Retrotransposons, a major type of genetic mobile elements that occupy $43 \%$ of the human and $37 \%$ of the mouse genome (10), encode RT and other proteins necessary for their mobilization. They are transcriptionally expressed in male and female gametes $(11,12)$, while heritable retrotranspositions have been documented in the germline and in embryos during the early stages of development (13). Finally, an RT activity, possibly of retrotransposon origin, 
has been revealed in mouse epididymal spermatozoa, which mediates the reverse transcription of exogenous RNA molecules to cDNA (14).

The RT has been a target of many antiretroviral drugs used in the treatment of HIV and hepatitis patients. Several studies have reported the negative effects of antiretroviral drugs on sperm parameters of HIV-infected patients, such as low ejaculate volumes, decreased sperm motility rates and high abnormal sperm morphology rates (15-17).

Taking into account the RT activity of the telomerase complex, the retrotransposition events during gametogenesis and early embryogenesis, the encoded transcriptase activity in mature spermatozoa as well as the impaired sperm parameters of HIV-patients undergoing antiretroviral therapy, we sought to explore the effects of the potent RT inhibitor lamivudine in mouse gametogenesis, oogenesis and embryo preimplantation development.

\section{Materials and Methods}

Animals. Inbred $\mathrm{FVB} / \mathrm{N}$ mice were provided by the Breeding Laboratory Animal Institute (Ioannina University Medical School, Greece). Animals were kept under a controlled $12 \mathrm{~h}$ light- $12 \mathrm{~h}$ dark life cycle with free access to standard diet and water. The General Directorate of Agricultural Economics and Veterinary Medicine of Epirus Region, Greece, approved the research protocols used. All research animals were treated in compliance with the European Union guidelines for the care and use of animals approved by our institution in accordance to principles of laboratory animal breeding and handling.

Study design. Thirty male and thirty female mice were randomly divided in two groups. The $1^{\text {st }}$ group (Control group) received 0.2 $\mathrm{ml}$ of intraperitoneal saline and the $2^{\text {nd }}$ group (lamivudine treated group) received $50 \mathrm{mg} / \mathrm{kg}$ of the nucleoside analogue RT inhibitor lamivudine for five consecutive days per week, for a total period of seven weeks (18). Lamivudine was diluted in dimethyl sulfoxide (DMSO) and injected in $0.2 \mathrm{ml}$ saline. The same volume of DMSO, without lamivudine, was injected in $0.2 \mathrm{ml}$ saline in control samples.

Histology examination. Testes and ovaries were fixed in neutral buffered formalin, embedded in paraffin, cut in $4 \mu \mathrm{m}$ thick sections and stained with hematoxylin-eosin. Histological examinations of tissues were conducted under light microscopy.

Sperm analysis. Spermatozoa collected from cauda epididymis were immediately transferred in culture medium (Sydney IVF Sperm Medium, COOK, Limerick, Ireland) under mineral oil (Sydney IVF Culture Oil, COOK, Limerick, Ireland) and were allowed to disperse in it by incubation for $20 \mathrm{~min}$ at $37^{\circ} \mathrm{C}$ in an atmosphere of $5 \% \mathrm{CO}_{2}$.

Shortly after the isolation, one drop of each sperm suspension was placed on a microscope slide and the motility was estimated microscopically at a magnification of $40 x$. After scoring two hundred spermatozoa per slide, the motility was classified as either of the following three classes: rapid progressive, slow progressive and non-progressive. Sperm count was calculated in well-mixed sperm suspensions using a Neubauer chamber. Morphological abnormalities, regarding head and tail defects, were assessed by
Papanicolaou staining. Two hundred spermatozoa per sample were counted and abnormal sperm percentages were calculated (19).

The sperm chromatin structure assay (SCSA) was used to determine fragmentation of sperm DNA, according to a protocol previously described (20). Spermatozoa were stained with Acridine Orange. The green (BP 530/30 filter) and red fluorescences (BP 650LP filter) were measured for 30,000 cells per sample after excitation with a $488 \mathrm{~nm}$ argon laser. Data analysis was performed by the Facscalibur Flow Cytometer (Becton Dickinson, San Jose, CA, USA).

In vitro fertilization experiments. In order to study its effect on mouse embryo preimplantation development, lamivudine was supplemented at a concentration of $200 \mu \mathrm{M}$ (21) in fertilization medium and in cleavage medium from pronuclear to blastocyst stage. Lamivudine was diluted in DMSO and was added in culture media at a volume of $0.25 \%$. The same volume of DMSO, without lamivudine, was added in media used in control samples.

In vitro fertilization process, including sperm preparation, ovarian stimulation and embryo preimplantation development, were carried out according to previously described protocol (22). In brief, sperm was collected from cauda epididymis and motile spermatozoa were selected using the Swim Up method. Sperm concentration was calculated using a Neubauer chamber. Sperm samples were left to be capacitated for $1.5 \mathrm{~h}\left(37^{\circ} \mathrm{C}, 5 \% \mathrm{CO}_{2}\right)$ in the proper fertilization medium (Sydney IVF Fertilization Medium, COOK) under mineral oil. Mature oocytes were retrieved from the oviducts of female mice after ovarian stimulation with an intraperitoneal injection (IP) of 8 IU follicle stimulating hormone (rec-FSH, Gonal-F, Merk Serono, London, UK), followed by an IP injection of 5IU of human chorionic gonadotropin 48 hours later (hCG, Pregnyl, N.V. Organon, Oss, the Netherlands). The in vitro fertilization was achieved by incubating oocytes with sperm in the above-mentioned fertilization medium for $5 \mathrm{~h}$. Afterwards, the oocytes were washed in order to remove the excess spermatozoa. Fertilized embryos were cultured in cleavage and blastocyst medium (Sydney IVF Cleavage Medium \& Sydney IVF Blastocyst Medium, COOK) until the blastocyst stage $\left(37^{\circ} \mathrm{C}, 5 \% \mathrm{CO}_{2}\right)$.

\section{Results}

The effect of Lamivudine on testis and ovarian histology. In order to study the effect of the reverse transcriptase (RT) inhibition on gametogenesis, the nucleoside analogue lamivudine was injected in male and female mice for five consecutive days per week, for a total period of seven weeks. After treatment, ovarian and testicular histological analysis was performed, while sperm parameters were evaluated.

Representative testicular and ovarian histological sections of the Control (A) and the lamivudine treated groups (B) are shown in Figures 1 and 2, respectively. The seminiferous tubule structure of lamivudine treated animals was found to be significantly impaired, while a noticeable reduction of Sertoli cells and germ cells of various differentiation stages was also observed.

The number of primordial germ cells was significantly reduced in the lamivudine treated female animals compared to the control group $(6.50 \pm 1.38$ vs. $22.33 \pm 3.72, p<0.001$, 

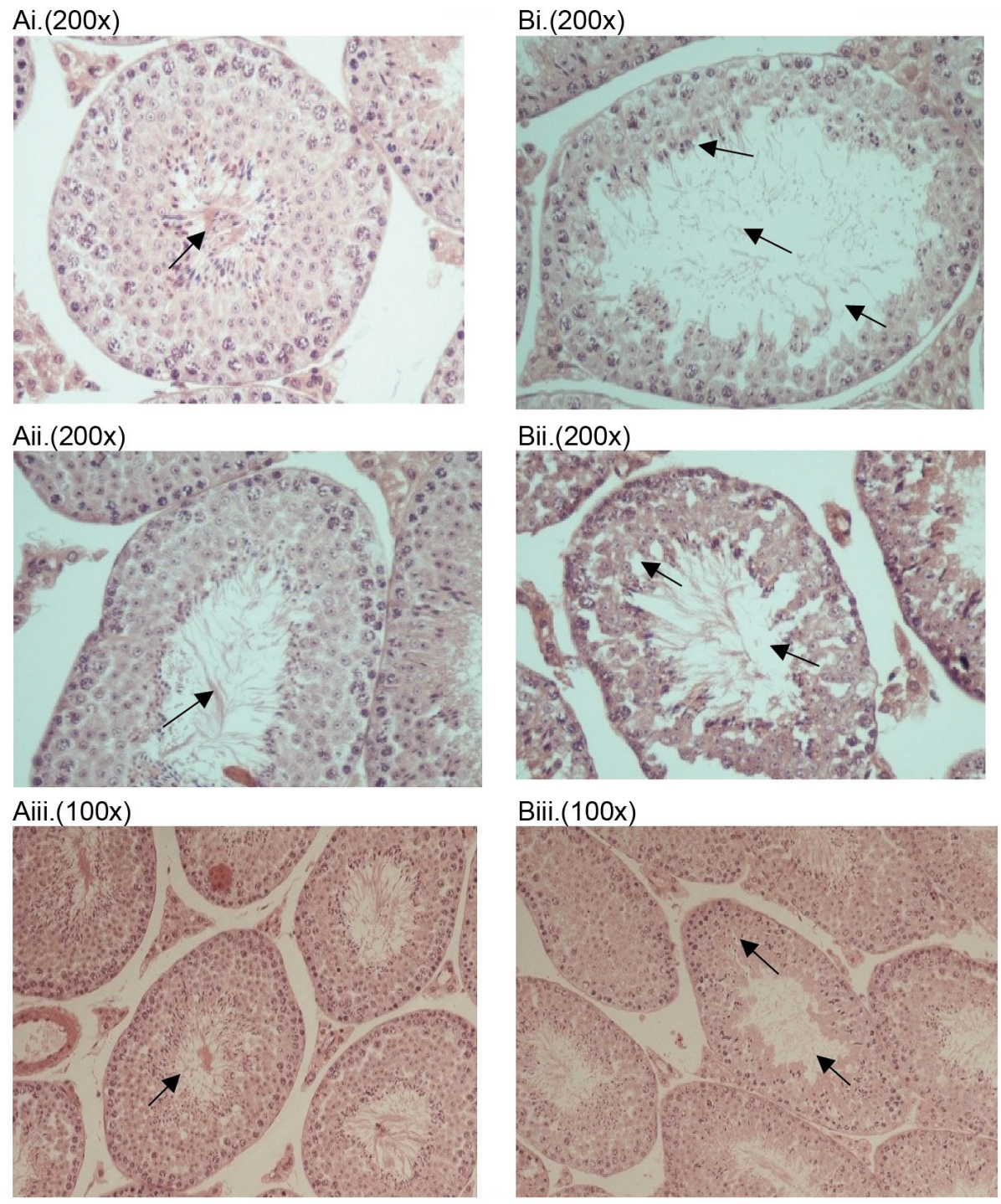

A. Control group

B. Lamivudine treated group

Figure 1. Testicular histological sections in the: A) control group and B) lamivudine treated group. Lamivudine was injected into male FVB/N mice at a concentration of $50 \mathrm{mg} / \mathrm{kg}$ for five consecutive days for a total period of seven weeks.

respectively). The number of primary oocytes was also lower in the lamivudine treated group compared to the control group $(6.33 \pm 2.16$ vs. $9.83 \pm 2.32, p=0.022$, respectively). However, no statistically significant difference was observed in the mean number of corpus luteum (lamivudine treated group: $6.83 \pm 2.40$ corpus luteum vs. control group: $5.00 \pm 2.00, p>0.05)$ and in the maximum ovarian diameter (lamivudine treated group: $2.83 \pm 0.98 \mathrm{~cm} v s$. Control group: $2.83 \pm 0.41 \mathrm{~cm}, p>0.05)$ between the two groups. Finally, a slight increase in the number of atretic oocytes was observed in the lamivudine treated animals $(4.50 \pm 2.43$ vs. $2.67 \pm 1.21$, $p>0.05$, respectively).
The effect of lamivudine on sperm parameters. Sperm analysis was performed in cauda epididymis spermatozoa of the control and the lamivudine treated animals. Sperm concentration and motility were determined by microscopy (40× magnification) shortly after sperm isolation. All sperm parameters presented noteworthy impairment in the lamivudine group compared to the control group. The epididymis sperm concentration in the control group was $31.67 \pm 3.67 \times 10^{6}$ spermatozoa $/ \mathrm{ml}$, while in the lamivudine treated group was only $22.78 \pm 2.22 \times 10^{6}$ spermatozoa $/ \mathrm{ml}$ $(p>0.05)$. In the control group, $49.05 \pm 3.82 \%$ of the spermatozoa presented with rapid progressive motility, 
Ai.

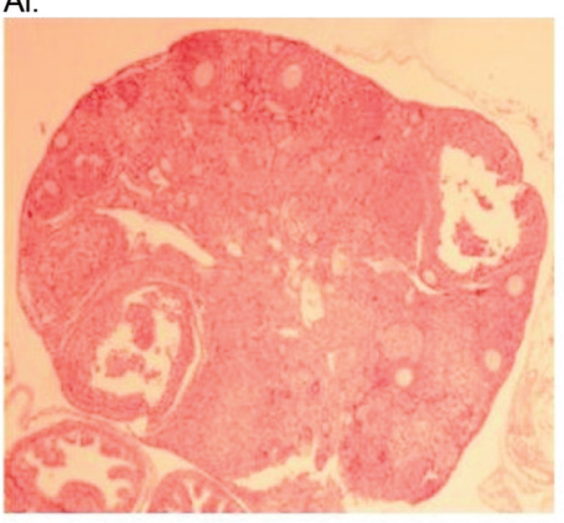

Aii.

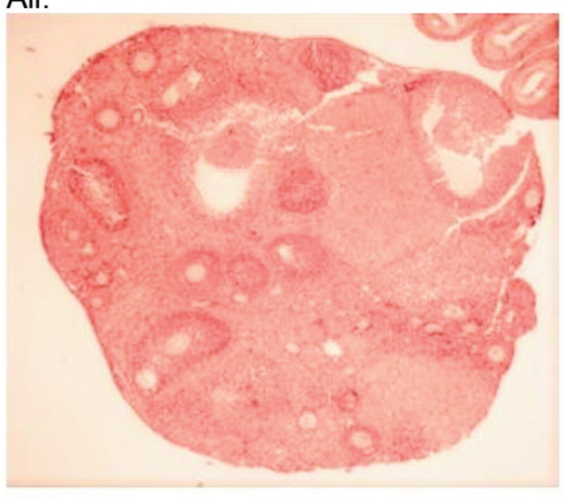

A. Control group
Bi.

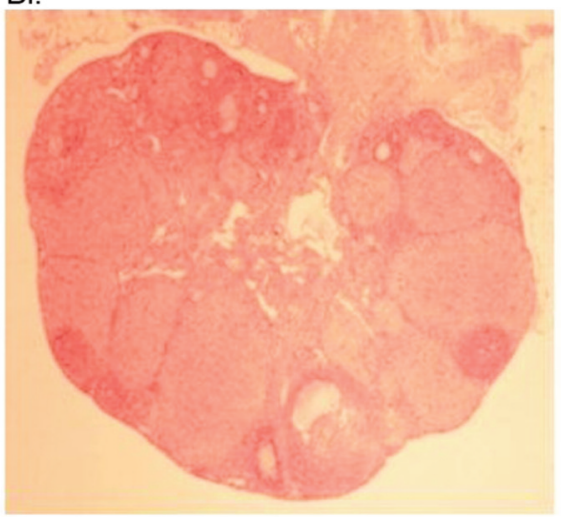

Bii.

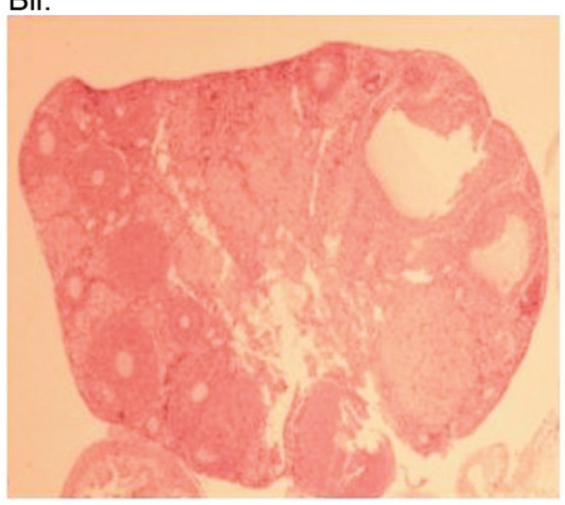

B. Lamivudine treated group

Figure 2. Ovarian histological sections in the A) control group (40x) and B) lamivudine treated group (40x). Lamivudine was injected into female $\mathrm{FVB} / \mathrm{N}$ mice at a concentration of $50 \mathrm{mg} / \mathrm{kg}$ for five consecutive days for a total period of seven weeks.

$21.66 \pm 3.76 \%$ with slow progressive motility, $17.55 \pm 2.48 \%$ with slow circular movement, while the remaining $11.74 \pm 1.58 \%$ of the spermatozoa were immotile. In contrast, in the lamivudine treated group, only $7.22 \pm 1.73 \%$ of the spermatozoa presented with rapid progressive motility, $17.14 \pm 2.69 \%$ with slow progressive motility, $28.44 \pm 2.42 \%$ with slow circular movement, while the remaining $47.2 \pm 3.74 \%$ of the spermatozoa were immotile (Table I).

The morphology and nuclear chromatin integrity of the sperm cells were assessed by Papanicolaou staining (Figure 3 ) and chromatin structure assay, respectively. Increased rates of morphological abnormality were observed in the lamivudine treated group compared to the control group. Specifically, in the lamivudine group, only $22.93 \pm 1.73 \%$ of the spermatozoa had normal morphology, $45.93 \pm 2.75 \%$ had no tail, $24.13 \pm 1.05 \%$ had bent tail, $12.96 \pm 0.38 \%$ had coiled tail and $5.71 \pm 1.35 \%$ of them had head abnormalities. In contrast, in the control group, $75.14 \pm 1.63 \%$ of the spermatozoa presented with normal morphology, $6.69 \pm 1.27 \%$ with no tail, $12.31 \pm 2.99 \%$ with bent tail, $2.29 \pm 0.98 \%$ with coiled tail and $3.58 \pm 0.56 \%$ with head abnormalities (Table I). The nuclear chromatin integrity was slightly decreased in the lamivudine treated animals compared to the control group (84.84 \pm 4.88 vs. $90.97 \pm 2.49, p>0.05)$.

The effect of lamivudine on mouse embryo preimplantation development. In order to address its impact on mouse embryo preimplantation development, lamivudine was added at a concentration of $200 \mu \mathrm{M}$ in the fertilization medium and in the cleavage medium during embryo development until the blastocyst stage.

The control group comprised 120 embryos, while the lamivudine treated group 110 embryos. The in vitro preimplantation development of mouse embryos was scored daily until the blastocyst stage. The developmental stages at which lamivudine exposed embryos were arrested are presented in Figure 3. A considerable number of these embryos had dramatically altered morphology and were arrested before the formation of blastocyst, indicating that the presence of the RT inhibitor negatively affected the 
Table I. Sperm parameters in the control and lamivudine treated groups.

\begin{tabular}{lccc}
\hline Sperm Parameters & Control group & $\begin{array}{c}\text { Lamivudine } \\
\text { treated group }\end{array}$ & $p$-Value \\
\hline $\begin{array}{l}\text { Concentration } \\
\left(\times 10^{6} \text { spermatozoa/ml }\right)\end{array}$ & $31.67 \pm 3.67$ & $22.78 \pm 2.22$ & $\mathrm{~ns}$ \\
$\begin{array}{l}\text { Nuclear chromatin integrity } \\
\text { Motility (\%) }\end{array}$ & $90.97 \pm 2.49$ & $84.84 \pm 4.88$ & $\mathrm{~ns}$ \\
$\quad$ & & \\
a. Rapid progressive & $49.05 \pm 3.82$ & $7.22 \pm 1.73$ & 0.037 \\
b. Slow progressive & $21.66 \pm 3.76$ & $17.14 \pm 2.69$ & $\mathrm{~ns}$ \\
c. Non-progressive & $17.55 \pm 2.48$ & $28.44 \pm 2.42$ & $\mathrm{~ns}$ \\
$\quad$ d. No motility & $11.74 \pm 1.58$ & $47.2 \pm 3.74$ & $\mathrm{~ns}$ \\
Morphology (\%) & & & \\
a. Normal & $75.14 \pm 1.63$ & $22.93 \pm 1.73$ & $\mathrm{~ns}$ \\
b. Bent tail & $12.31 \pm 2.99$ & $24.13 \pm 1.05$ & 0.033 \\
c. No tail & $6.69 \pm 1.27$ & $45.93 \pm 2.75$ & 0.05 \\
$\quad$ d. Coiled tail & $2.29 \pm 0.98$ & $12.96 \pm 0.38$ & 0.05 \\
e. Head abnormalities & $3.58 \pm 0.56$ & $5.71 \pm 1.35$ & $\mathrm{~ns}$ \\
\hline
\end{tabular}

All parameters are presented as mean value \pm standard deviation. ns: Non-significant.

preimplantation development of embryos. Specifically, although $85 \%$ of the control embryos reached the blastocyst stage, only $55 \%$ of the lamivudine exposed embryos formed a blastocyst, while $34 \%$ of them were arrested at the stages of 2-10 cells.

\section{Discussion}

Reverse transcriptase (RT) mediates the reverse flow of genetic information from RNA to DNA. It is essential for the retrovirus lifecycle, the telomerase function and the intracellular retroelement replication in eukaryotic cells. The reverse transcriptase activity during gametogenesis has been associated with the telomerase activity and the retroelement expression, suggesting an essential role of RT function in the structural and functional maturation of ova and spermatozoa $(8,9,11,12,14)$. To investigate the role of RT on gametogenesis, we administered the nucleoside analog reverse transcriptase inhibitor lamivudine in male and female mice for a total period of seven weeks. Testicular and ovarian structure defects, decreased sperm quality and impaired embryo preimplantation development were observed following treatment.

The administration of lamivudine affected the testicular and the ovarian tissue structure of the treated animals. Specifically, the seminiferous tubule cellular organization was significantly impaired in lamivudine treated animals possibly due to the remarkable reduction in the number of Sertoli cells. Extensive gaps along the whole tubule surface not only decreased the number of germ cells, which progressively develop and differentiate into mature gametes, but also reversed the movement of mature spermatids and spermatozoa from the tubule lumen towards the basement membrane. The decrease in sperm concentration and the noteworthy alterations in the sperm motility and morphology reflect the impaired function of the seminiferous tubule. A considerable proportion of spermatozoa was immotile or was characterized by a slow circular movement. Regarding the morphological defects, most of them were observed in the midpiece or the neck of spermatozoa and more rarely in the head. Moreover, condensation of the sperm chromatin was slightly decreased in the lamivudine exposed group as compared to the control group. However, female mice of the lamivudine group presented with a significant decrease in the number of primary oocytes. Furthermore, an increase of atretic follicles was observed in the ovaries of the treated animals resembling those of women with PCOS. Finally, lamivudine impaired the in vitro preimplantation development of mouse embryos causing accelerated asymmetrical cell divisions, multiple cellular fragments and arrest at the stages of 2-10 cells.

Lamivudine as a nucleoside analog RT inhibitor probably exerted its side effects through the prevention of DNA polymerization leading to incomplete Sertoli cells proliferation and to inappropriate germ cell growth and differentiation. Additionally, the processes of gametogenesis and embryogenesis were possibly impaired through the inhibition of the retrotransposon transcription and the telomerase inactivation. Indeed, the functional inactivation of two RT encoded elements, LINE-1 and MuRV-1, and the exposure of mouse embryos in nevirapine, a non-nucleosideanalog reverse transcriptase inhibitor, have been shown to impair the early preimplantation development in mouse embryos (23), indicating the significant role of RT activity in embryogenesis. Additionally, it has been reported in in vitro studies that lamivudine and other commonly used antiretroviral drugs have significantly impaired telomerase activity and telomere length (24). Zivodune (AZT), a nucleoside analog RT inhibitor, has exhibited preferential incorporation into telomere sequences of immortalized cell lines, potentially telomerase mediated, leading to a marked progressive telomere shortening. An extended telomere length shortening may cause cell cycle arrest and cell replicative senescence (25-27). It has been reported that insufficient telomerase activity and short telomere length may adversely affect many cellular developmental events like chromosome segregation, viability, sperm population and fertility (28). Furthermore, absence of telomerase activity in abnormal oocytes has been associated with reproductive senescence and chromosomal abnormalities (9), while fertilized telomerase-deficient oocytes exhibit aberrant cleavage and embryo development. Finally, the lack of granulose telomerase activity and the short telomeres in women have been correlated with ovarian insufficiency (7). Further studies are needed to examine the relationship between telomerase and retrotransposons' RT activity and to 
Ai.

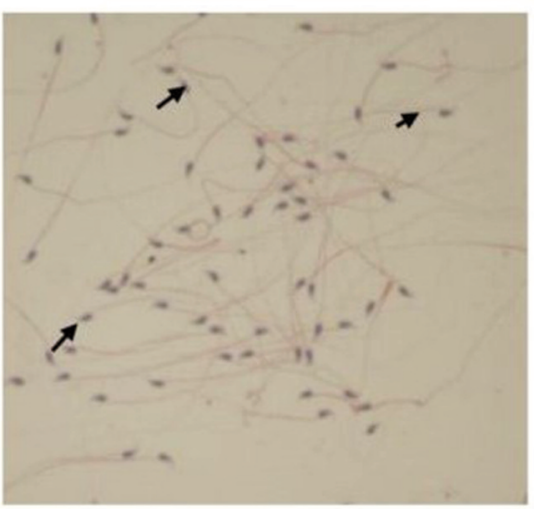

Aii.

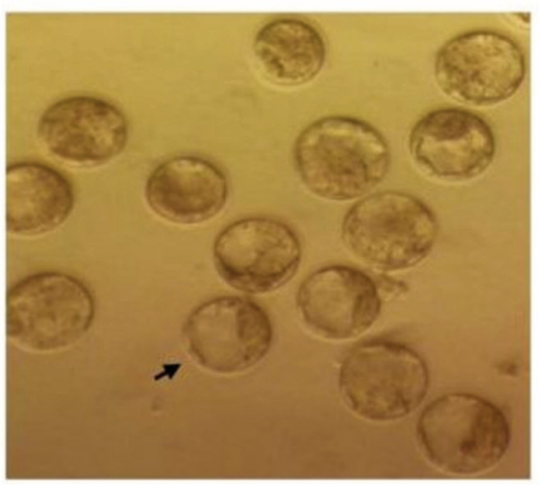

A. Control group

定

동

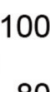

80

峁 60

40

尺े 20

है 0

(1)
Bi.

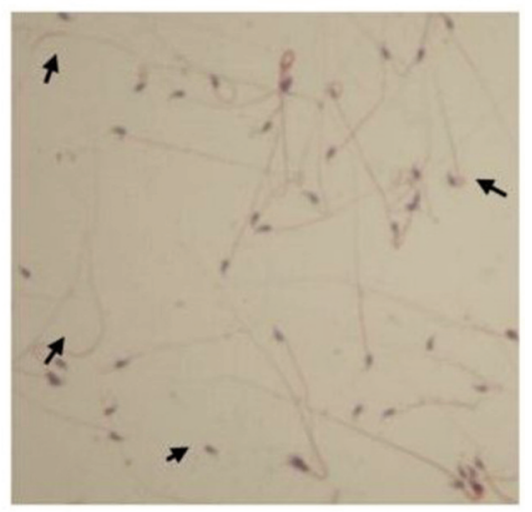

Bii.

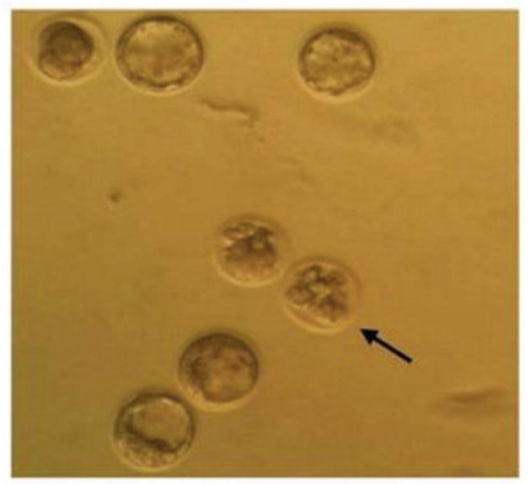

B. Lamivudine treated group

\section{C.}

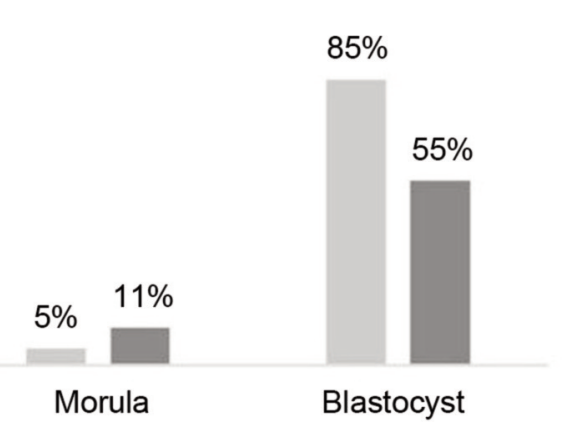

\section{- Control = Lamivudine}

Figure 3. A. Sperm cell and embryo morphology in the A) control group and B) lamivudine treated group. C. Developmental stage at which embryos of the control group and lamivudine treated group were arrested. Embryos were exposed to $200 \mu M$ lamivudine from the fertilization process through to the blastocyst stage.

clarify if they act synergistically or not, in order to control the processes of gametogenesis and embryonic development.

Several studies have reported the adverse effects of antiretroviral drugs on sperm parameters of HIV-infected patients and specifically the decreased ejaculate volume, sperm motility and normal sperm morphology $(15,16,29)$.
The study of the toxicological effects of nevirapine on Wistar rat testes has shown testicular lipid peroxidation (LPO) elevation that may be related to sperm morphology, motility and viability defects (30). Moreover, AF/ABDP cis, a rifampicin derivative, has induced ultrastructural alterations of pachytenes oocytes and mitochondrial damage in all ovarian 
cells of Xenopus laevis (31). Finally, the administration of AZT in pregnant mice has resulted in embryo death during the first half of gestation, while the direct exposure of developing embryos to AZT has retarded embryo cell divisions and impaired developmental ability (32).

Our results agree with the findings of previous studies, verifying the negative effects of RT inhibitors on cell proliferation during gametogenesis. To conclude, the administration of lamivudine in male and female mice negatively affects the testicular/ovarian structure and function. Lamivudine causes seminiferous tubule structure disorganization, increased abnormal sperm morphology and DNA degradation, as found by the SCSA analysis of sperm. In the ovaries, the afore-mentioned inhibition leads to the formation of multiple cysts, increased preantral follicle numbers and low corpus luteum numbers. Notably, the toxic effects of the RT inhibitor lamivudine on the structure and function of the reproductive organs, the preimplantation development as well as the reproductive outcome reveal the fundamental contribution of RT, either of telomerase or retrotransposable origin, on cell growth, proliferation and differentiation control. Future studies examining consequent mice generations are needed to elucidate the negative effects of lamivudine treatment on the offspring. These studies will enrich our knowledge on the mechanism by which RT controls critical reproductive events like gametogenesis and mouse preimplantation development in mammals.

\section{Conflicts of Interest}

The Authors declare that they have no conflicts of interest regarding this study.

\section{Authors' Contributions}

C.K., L.L. and I.G. conceived and designed the study; C.K., L.L, A.P., P.P., E.M., T.L., K. G., I. B., G.V., S.M., A.B. conducted the experiments; C.K. and LL. analyzed the data; C.K., L.L. and I.G. wrote the paper; C.K., L.L., A.B., and I.G. discussed the manuscript and provided important feedback; I.G. supervised the project.

\section{Acknowledgements}

This research has been co-financed by the European Union (European Social Fund - ESF) and Greek national funds through the Operational Program "Education and Lifelong Learning" of the National Strategic Reference Framework (NSRF) - Research Funding Program: Heracleitus II. Investing in knowledge society through the European Social Fund.

\section{References}

1 Verma IM: The reverse transcriptase. Biochim Biophys Acta 473(1): 1-38, 1977. PMID: 66065. DOI: 10.1016/0304$419 x(77) 90005-1$
2 Telesnitsky A and Goff SP: Reverse transcriptase and the generation of retroviral DNA. In: Retroviruses. Coffin JM, Hughes SH and Varmus HE (eds.). Cold Spring Harbor Laboratory Press: Cold Spring Harbor (NY), 1997. PMID: 21433342.

3 Nisole S and Saib A: Early steps of retrovirus replicative cycle. Retrovirology 1: 9, 2004. PMID: 15169567. DOI: 10.1186/17424690-1-9

4 Kazazian HH Jr.: Mobile elements: Drivers of genome evolution. Science 303(5664): 1626-1632, 2004. PMID: 15016989. DOI: $10.1126 /$ science. 1089670

5 Autexier $\mathrm{C}$ and Lue NF: The structure and function of telomerase reverse transcriptase. Annu Rev Biochem 75: 493517, 2006. PMID: 16756500. DOI: 10.1146/annurev.biochem. 75.103004 .142412

6 Weikert S, Christoph F, Schulze W, Krause H, Kempkensteffen C, Schostak M, Miller K and Schrader M: Testicular expression of survivin and human telomerase reverse transcriptase (htert) associated with spermatogenic function in infertile patients. Asian J Androl 8(1): 95-100, 2006. PMID: 16372125. DOI: $10.1111 / \mathrm{j} .1745-7262.2006 .00102 . \mathrm{x}$

7 Liu JP and Li H: Telomerase in the ovary. Reproduction 140(2): 215-222, 2010. PMID: 20562297. DOI: 10.1530/REP-10-0008

8 Wright WE, Piatyszek MA, Rainey WE, Byrd W and Shay JW: Telomerase activity in human germline and embryonic tissues and cells. Dev Genet 18(2): 173-179, 1996. PMID: 8934879. DOI: 10.1002/(SICI)1520-6408(1996)18:2<173::AID-DVG10> 3.0.CO;2-3

9 Bekaert S, Derradji H and Baatout S: Telomere biology in mammalian germ cells and during development. Dev Biol 274(1): 15-30, 2004. PMID: 15355785. DOI: 10.1016/j.ydbio.2004.06.023

10 Lander ES, Linton LM, Birren B, Nusbaum C, Zody MC, Baldwin J, Devon K, Dewar K, Doyle M, FitzHugh W, Funke R, Gage D, Harris K, Heaford A, et al.: Initial sequencing and analysis of the human genome. Nature 409(6822): 860-921, 2001. PMID: 11237011 . DOI: $10.1038 / 35057062$

11 Branciforte D and Martin SL: Developmental and cell type specificity of line-1 expression in mouse testis: Implications for transposition. Mol Cell Biol 14(4): 2584-2592, 1994. PMID: 8139560. DOI: $10.1128 / \mathrm{mcb} .14 .4 .2584$

12 Georgiou I, Noutsopoulos D, Dimitriadou E, Markopoulos G, Apergi A, Lazaros L, Vaxevanoglou T, Pantos K, Syrrou M and Tzavaras T: Retrotransposon rna expression and evidence for retrotransposition events in human oocytes. Hum Mol Genet 18(7): 1221-1228, 2009. PMID: 19147684. DOI: 10.1093/ $\mathrm{hmg} / \mathrm{ddp} 022$

13 Kano H, Godoy I, Courtney C, Vetter MR, Gerton GL, Ostertag EM and Kazazian HH, Jr.: L1 retrotransposition occurs mainly in embryogenesis and creates somatic mosaicism. Genes Dev 23(11): 1303-1312, 2009. PMID: 19487571. DOI: 10.1101/gad.1803909

14 Giordano R, Magnano AR, Zaccagnini G, Pittoggi C, Moscufo $\mathrm{N}$, Lorenzini R and Spadafora C: Reverse transcriptase activity in mature spermatozoa of mouse. J Cell Biol 148(6): 1107-1113, 2000. PMID: 10725323. DOI: 10.1083/jcb.148.6.1107

15 Nicopoullos JD, Almeida PA, Ramsay JW and Gilling-Smith C: The effect of human immunodeficiency virus on sperm parameters and the outcome of intrauterine insemination following sperm washing. Hum Reprod 19(10): 2289-2297, 2004. PMID: 15242991. DOI: 10.1093/humrep/deh426 
16 Bujan L, Sergerie M, Moinard N, Martinet S, Porte L, Massip P, Pasquier $\mathrm{C}$ and Daudin $\mathrm{M}$ : Decreased semen volume and spermatozoa motility in hiv-1-infected patients under antiretroviral treatment. J Androl 28(3): 444-452, 2007. PMID: 17215546. DOI: 10.2164/jandrol.106.001529

17 van Leeuwen E, Wit FW, Repping S, Eeftinck Schattenkerk JK, Reiss P, van der Veen F and Prins JM: Effects of antiretroviral therapy on semen quality. Aids 22(5): 637-642, 2008. PMID: 18317005. DOI: 10.1097/QAD.0b013e3282f4de10

18 Zhang Y, Song F, Gao Z, Ding W, Qiao L, Yang S, Chen X, Jin $\mathrm{R}$ and Chen $\mathrm{D}$ : Long-term exposure of mice to nucleoside analogues disrupts mitochondrial DNA maintenance in cortical neurons. PLoS One 9(1): e85637, 2014. PMID: 24465628. DOI: 10.1371/journal.pone. 0085637

19 Laboratory manual of the who for the examination of human semen and sperm-cervical mucus interaction. Ann Ist Super Sanita 37(1): I-XII, 1-123, 2001. PMID: 11680039.

20 Lazaros LA, Vartholomatos GA, Hatzi EG, Kaponis AI, Makrydimas GV, Kalantaridou SN, Sofikitis NV, Stefos TI, Zikopoulos KA and Georgiou IA: Assessment of sperm chromatin condensation and ploidy status using flow cytometry correlates to fertilization, embryo quality and pregnancy following in vitro fertilization. J Assist Reprod Genet 28(10): 885-891, 2011. PMID: 21779786. DOI: $10.1007 / \mathrm{s} 10815-011-9611-\mathrm{z}$

21 Pittoggi C, Sciamanna I, Mattei E, Beraldi R, Lobascio AM, Mai A, Quaglia MG, Lorenzini $\mathrm{R}$ and Spadafora C: Role of endogenous reverse transcriptase in murine early embryo development. Mol Reprod Dev 66(3): 225-236, 2003. PMID: 14502601. DOI: $10.1002 / \mathrm{mrd} .10349$

22 Kitsou C, Lazaros L, Bellou S, Vartholomatos G, Sakaloglou P, Hatzi E, Markoula S, Zikopoulos K, Tzavaras T and Georgiou I: Exogenous retroelement integration in sperm and embryos affects preimplantation development. Reproduction 152(3): 185193, 2016. PMID: 27450800. DOI: 10.1530/REP-15-0174

23 Beraldi R, Pittoggi C, Sciamanna I, Mattei E and Spadafora C: Expression of line-1 retroposons is essential for murine preimplantation development. Mol Reprod Dev 73(3): 279-287, 2006. PMID: 16365895. DOI: 10.1002/mrd.20423

24 Leeansyah E, Cameron PU, Solomon A, Tennakoon S, Velayudham P, Gouillou M, Spelman T, Hearps A, Fairley C, Smit de V, Pierce AB, Armishaw J, Crowe SM, Cooper DA, Koelsch KK, Liu JP, Chuah J and Lewin SR: Inhibition of telomerase activity by human immunodeficiency virus (hiv) nucleos(t)ide reverse transcriptase inhibitors: A potential factor contributing to hiv-associated accelerated aging. J Infect Dis 207(7): 1157-1165, 2013. PMID: 23303810. DOI: 10.1093/infdis/jit006
25 Gomez DE, Tejera AM and Olivero OA: Irreversible telomere shortening by 3'-azido-2',3'-dideoxythymidine (azt) treatment. Biochem Biophys Res Commun 246(1): 107-110, 1998. PMID: 9600076. DOI: $10.1006 / \mathrm{bbrc} .1998 .8555$

26 Strahl C and Blackburn EH: Effects of reverse transcriptase inhibitors on telomere length and telomerase activity in two immortalized human cell lines. Mol Cell Biol 16(1): 53-65, 1996. PMID: 8524329 . DOI: $10.1128 / \mathrm{mcb} \cdot 16.1 .53$

27 Murakami J, Nagai N, Shigemasa K and Ohama K: Inhibition of telomerase activity and cell proliferation by a reverse transcriptase inhibitor in gynaecological cancer cell lines. Eur J Cancer 35(6): 1027-1034, 1999. PMID: 10533489. DOI: 10.1016/s0959-8049(99)00037-4

28 Thilagavathi J, Venkatesh S and Dada R: Telomere length in reproduction. Andrologia 45(5): 289-304, 2013. PMID: 22928904. DOI: $10.1111 /$ and.12008

29 Lambert-Niclot S, Poirot C, Tubiana R, Houssaini A, Soulie C, Dominguez S, Schubert B, Prades M, Bonmarchand M, Calvez V, Flandre P, Peytavin G and Marcelin AG: Effect of antiretroviral drugs on the quality of semen. J Med Virol 83(8): 1391-1394, 2011. PMID: 21678443. DOI: 10.1002/jmv.22119

30 Adaramoye OA, Adesanoye OA, Adewumi OM and Akanni O: Studies on the toxicological effect of nevirapine, an antiretroviral drug, on the liver, kidney and testis of male wistar rats. Hum Exp Toxicol 31(7): 676-685, 2012. PMID: 22027508. DOI: 10.1177/0960327111424304

31 Steens M: Cytotoxic effect of a reverse transcriptase inhibitor, af/abdp cis, on ovaries of young xenopus laevis--ultrastructural and autoradiographic study. Chem Biol Interact 18(1): 59-67, 1977. PMID: 70278. DOI: 10.1016/0009-2797(77)90141-7

32 Toltzis P, Mourton T and Magnuson T: Effect of zidovudine on preimplantation murine embryos. Antimicrob Agents Chemother 37(8): 1610-1613, 1993. PMID: 8215271. DOI: 10.1128/ aac. 37.8 .1610

Received April 21, 2020

Revised May 4, 2020

Accepted May 5, 2020 